\section{Case Reports in Ophthalmology}

\title{
Central Retinal Vein Occlusion in 2 Patients Using Antipsychotic Drugs
}

\author{
Koichiro Taki Teruyo Kida Masanori Fukumoto Takaki Sato \\ Hidehiro Oku Tsunehiko Ikeda \\ Department of Ophthalmology, Osaka Medical College, Takatsuki, Japan
}

\section{Keywords}

Central retinal vein occlusion - Antipsychotic drug - Venous thromboembolism .

Cotton wool spots - Macular edema - Anti-VEGF therapy

\begin{abstract}
Purpose: To report our findings in 2 patients who developed a central retinal vein occlusion (CRVO) and were chronic users of antipsychotic medications. Case Presentation: Case 1 was a 62-year-old woman who had a sudden reduction of vision in her right eye to 20/2,000. Her fundus showed signs of an impending CRVO with marked macular edema. She had been taking antipsychotic drugs (quetiapine fumarate and risperidone) for about 2 years. She refused anti-VEGF therapy for her macular edema but selected systemic kallidinogenase. Two days later, the macular edema was significantly reduced but the number of cotton wool spots (CWS) was increased. Ten days later, the macular edema was resolved and her BCVA improved to 20/60. The CWS gradually disappeared, and her BCVA improved to 20/20. Case 2 was a 43-year-old man who presented with vision reduction in his right eye of 1 week's duration. His BCVA was 20/50 and his fundus showed signs of a CRVO-related macular edema with CWS in the peripapillary area. He had been taking sulpiride (Dogmaty $\left.\right|^{\top \mathrm{M}}$ ) for depression for 1 year, and his blood test showed an increase in red blood cells and hematocrit. AntiVEGF therapy was performed, and the macular edema was resolved with vision improving to 20/20. There has been no recurrence to date in both cases. Conclusions: These results indicate that a CRVO can be a complication of chronic use of antipsychotic medications. Howev-
\end{abstract}




\section{Case Reports in Ophthalmology}

er, early treatment can lead to good outcomes. Clinicians should question patients who develop a sudden CRVO whether they are using antipsychotic medications.

(C) 2017 The Author(s)

Published by S. Karger AG, Basel

\section{Introduction}

It is well known that some antipsychotic drugs are risk factors for venous thromboembolic (VTE) diseases such as deep venous thrombosis and pulmonary embolism [1-4]. This has been reported in a large primary care population [5] and in a Taiwanese population [6]. However, an association between antipsychotic drug use and a central retinal vein occlusion (CRVO) has rarely been reported.

We present out findings on 2 patients with CRVO-related macular edema with cotton wool spots (CWS). Both patients had been taking the antipsychotic drugs for a long time.

\section{Case Reports}

Case 1

A 62-year-old woman was referred to our clinic with a sudden reduction in vision in her right eye in May 2015. She had been diagnosed with a mental disorder 8 years earlier and was taking clonazepam, quetiapine fumarate, nitrazepam, and risperidone. Her BCVA was 20/2,000 in her right eye and 20/20 in her left eye. Her intraocular pressure was $15 \mathrm{~mm} \mathrm{Hg}$ in her right eye and $10 \mathrm{~mm} \mathrm{Hg}$ in her left eye. Slit-lamp examinations of the anterior segment of both eyes were normal without cataracts. Ophthalmoscopy showed a CRVO with severe macular edema in her right eye. The retinal veins were tortuous and dilated and hemorrhages and small CWS due to the CRVO were seen in her right fundus (Fig. 1a). Optical coherence tomography (OCT) showed severe macular edema with a high reflectivity of the inner retinal layer (Fig. 1b). Fluorescein angiography (FA) was performed to rule out ischemic CRVO and combined retinal artery occlusion. The arm-to-retina time was $15 \mathrm{~s}$. FA did not detect any arterial obstruction or nonperfused areas (Fig. 1c). We recommended intravitreal anti-VEGF therapy for her macular edema but she refused and selected systemic kallidinogenase. She continued with her antipsychotic medications.

Two days after beginning the kallidinogenase, the macular edema was significantly decreased but the number of the CWS was increased. The edema was resolved 10 days later and her VA improved to 20/60. The CWS gradually disappeared and her VA improved to $20 / 20$. However, the central retinal thickness was thin at $163 \mu \mathrm{m}$ in the OCT images obtained 1 year after the onset of the CRVO (Fig. 1d). There has been no recurrence to date.

Case 2

A 43-year-old man presented with a sudden, painless reduction in vision in his right eye of 1 week's duration. He had been taking sulpiride (Dogmatyl ${ }^{\mathrm{TM}}$ ), duloxetine, and clonazepam for depression for 1 year. His BCVA was 20/50 in his right eye and 20/20 in his left eye. The intraocular pressure was $10 \mathrm{~mm} \mathrm{Hg}$ in his right eye and $13 \mathrm{~mm} \mathrm{Hg}$ in his left eye. Anterior segment examinations were normal in both eyes and fundus examinations showed a CRVO in his right eye (Fig. 2a). The right optic disc was swollen, the retinal veins were tortuous and dilated, and retinal hemorrhages and small CWS were present in his right fundus. OCT showed marked macular edema (Fig. 2b). His blood test showed increased red 
blood cells (5.75 million/ $\mu$ l) and high hematocrit (50.4\%). His hemoglobin was $17.3 \mathrm{~g} / \mathrm{dL}$ which was within normal limits, and there was no finding of dehydration. FA showed no signs of ischemia (Fig. 2c). The arm-to-retina time was $14 \mathrm{~s}$.

With consent, ranibizumab was injected intravitreally for his CRVO-related macular edema. He continued to use his antipsychotic medications during the treatment. The macular edema was resolved 1 month after the single injection of ranibizumab and his BCVA improved to 20/20 (Fig. 2d). His VA has been maintained without recurrences to date (Fig. $2 \mathrm{e}, \mathrm{f})$.

\section{Discussion}

The findings in these 2 patients suggest that a CRVO with macular edema can be a complication of the chronic use of antipsychotic medications. Although the treatments were different in the 2 patients, both had a good resolution of the pathological changes and vision recovered to $20 / 20$.

A retinal vein occlusion occasionally leads to severe reduction of vision. Macular edema is the major vision-threatening complication associated with a CRVO [7-9]. Anti-VEGF therapy is currently the standard treatment for CRVO-related macular edema, and it is quite effective. The macular edema of case 2 was resolved by intravitreal ranibizumab with his vision improving to $20 / 20$.

The pathogenesis of a retinal vein occlusion has not been definitively determined [10]. The most recognized risk factors are age and systemic vascular disorders, although patients under the age of 45 can develop a CRVO [11]. Some CRVOs are associated with thrombophilic disorders $[11,12]$, and CRVOs can be due to a combination of different systemic disorders, e.g., hemodynamic changes (venous stasis), degenerative changes of the blood vessel wall, and blood hypercoagulability. It has also been suggested that hyperviscosity due to high hematocrit may play a role in the development of CRVOs. The higher blood viscosity would increase the aggregation of erythrocytes and slow the blood flow, thus increasing the possibility of clotting $[12,13]$. Case 2 had a high hematocrit count due to his antipsychotic medications.

Severe thromboembolic diseases such as pulmonary embolism and VTE have been reported to develop in patients being treated with antipsychotic agents, but the incidence was reported to be as low as $0.0091 \%$ [2]. The incidence for a retinal vein occlusion in patients taking antipsychotic medications has not been reported in Japan. A search of PubMed with key words "central retinal vein occlusion and antipsychotic drug" extracted only 1 publication by Agca et al. [14], and the phrase "branch retinal vein occlusion" extracted 1 publication by Yong et al. [15]. The authors reported on a 19-year-old patient taking risperidone and fluoxetine who developed an atypical nonischemic CRVO with deep intraretinal hemorrhages and a swollen optic disc. Our case 1 was also using risperidone but presented with marked macular edema. Case 2 had been taking sulpiride (Dogmatyl ${ }^{\mathrm{TM}}$ ), and his blood test showed an increase in the red blood cell count and hematocrit. The side effects of risperidone, quetiapine, and Dogmatyl ${ }^{\mathrm{TM}}$ are venous thrombosis and pulmonary embolisms $[2,5]$. These drugs were being used in our 2 cases. Risperidone has a high affinity to $5-\mathrm{HT}_{2 \mathrm{~A}}$, a serotonin receptor. $5-\mathrm{HT}_{2 \mathrm{~A}}$ blockers stimulate $5-\mathrm{HT}_{2 \mathrm{~A}}$ in the platelets and induce platelet aggregation, causing the vascular smooth muscles to contract $[16,17]$. Thus, platelet aggregation may have played a role in the CRVO in our patient. 
This study does have a limitation. These patients took several drugs, and we did not determine which one was the real culprit. The CRVO-related macular edema in case 1 recovered relatively quickly without discontinuation of the antipsychotic drugs. It would be helpful to measure the retinal venous pressure, particularly in the nonaffected contralateral eye $[18,19]$. If the retinal venous pressure is dependent on the intake of these antipsychotic drugs, we could have good evidence on a relationship between CRVO and antipsychotic drug use.

In conclusion, we examined 2 cases of CRVO with macular edema who were chronic antipsychotic drug users. We should note that CRVO can develop in patients taking antipsychotic drugs, and the CRVO can have different clinical courses.

\section{Acknowledgment}

The authors deeply thank Professor Emeritus Duco Hamasaki of the Bascom Palmer Eye Institute for discussions and editing.

\section{Statement of Ethics}

The authors have no ethical conflicts to disclose.

\section{Disclosure Statement}

The authors have no conflicts of interest to report.

\section{References}

1 Curtin F, Blum M: Antipsychotics and risk of venous thrombosis. Br J Psychiatry 2002;180:85. Liperoti R, Pedone C, Lapane KL, Mor V, Bernabei R, Gambassi G: Venous thromboembolism among elderly patients treated with atypical and conventional antipsychotic agents. Arch Intern Med 2005; 165:2677-2682.

3 Ray JG, Mamdani MM, Yeo EL: Antipsychotic and antidepressant drug use in the elderly and the risk of venous thromboembolism. Thromb Haemost 2002;88:205-209.

4 Thomassen R, Vandenbroucke JP, Rosendaal FR: Antipsychotic medication and venous thrombosis. Br J Psychiatry 2001;179:63-66.

5 Parker C, Coupland C, Hippisley-Cox J: Antipsychotic drugs and risk of venous thromboembolism: nested case-control study. BMJ 2010;341:c4245.

-6 Wu CS, Lin CC, Chang CM, Wu KY, Liang HY, Huang YW, et al: Antipsychotic treatment and the occurrence of venous thromboembolism: a 10-year nationwide registry study. J Clin Psychiatry 2013;74:918-924.

-7 Pe'er J, Folberg R, Itin A, Gnessin H, Hemo I, Keshet E: Vascular endothelial growth factor upregulation in human central retinal vein occlusion. Ophthalmology 1998;105:412-416.

-8 Campochiaro PA: Molecular pathogenesis of retinal and choroidal vascular diseases. Prog Retin Eye Res 2015;49:67-81.

-9 Yeh S, Kim SJ, Ho AC, Schoenberger SD, Bakri SJ, Ehlers JP, et al: Therapies for macular edema associated with central retinal vein occlusion: a report by the American Academy of Ophthalmology. Ophthalmology 2015;122:769-778.

10 Fraenkl SA, Mozaffarieh M, Flammer J: Retinal vein occlusions: the potential impact of a dysregulation of the retinal veins. EPMA J 2010;1:253-261.

11 Ehlers JP, Fekrat S: Retinal vein occlusion: beyond the acute event. Surv Ophthalmol 2011;56:281-299. 


\section{Case Reports in Ophthalmology}

\begin{tabular}{l|l}
\hline Case Rep Ophthalmol 2017;8:410-415 \\
\hline DOI: $10.1159 / 000479219$ & $\begin{array}{l}\text { C } 2017 \text { The Author(s). Published by S. Karger AG, Basel } \\
\text { www.karger.com/cop }\end{array}$ \\
\hline
\end{tabular}

Taki et al.: Central Retinal Vein Occlusion in 2 Patients Using Antipsychotic Drugs

12 Rehak M, Wiedemann P: Retinal vein thrombosis: pathogenesis and management. J Thromb Haemost 2010;8:1886-1894.

13 McGrath MA, Wechsler F, Hunyor AB, Penny R: Systemic factors contributory to retinal vein occlusion. Arch Intern Med 1978;138:216-220.

14 Agca A, Bayraktar Z, Cakr M, Bayraktar S, Ekinci O, Ylmaz OF: Central retinal vein occlusion in a young adult during risperidone therapy. Retin Cases Brief Rep 2008;2:199-201.

15 Yong KC, Kah TA, Ghee YT, Siang LC, Bastion ML: Branch retinal vein occlusion associated with quetiapine fumarate. BMC Ophthalmol 2011;11:24.

-16 Cerrito F, Lazzaro MP, Gaudio E, Arminio P, Aloisi G: $5 \mathrm{HT}_{2}$-receptors and serotonin release: their role in human platelet aggregation. Life Sci 1993;53:209-215.

-17 Dees C, Akhmetshina A, Zerr P, Reich N, Palumbo K, Horn A, et al: Platelet-derived serotonin links vascular disease and tissue fibrosis. J Exp Med 2011;208:961-972.

18 Mozaffarieh M, Bartschi M, Henrich PB, Schoetzau A, Flammer J: Retinal venous pressure in the nonaffected eye of patients with retinal vein occlusions. Graefes Arch Clin Exp Ophthalmol 2014;252:15691571.

19 Flammer J, Konieczka K: Retinal venous pressure: the role of endothelin. EPMA J 2015;6:21.
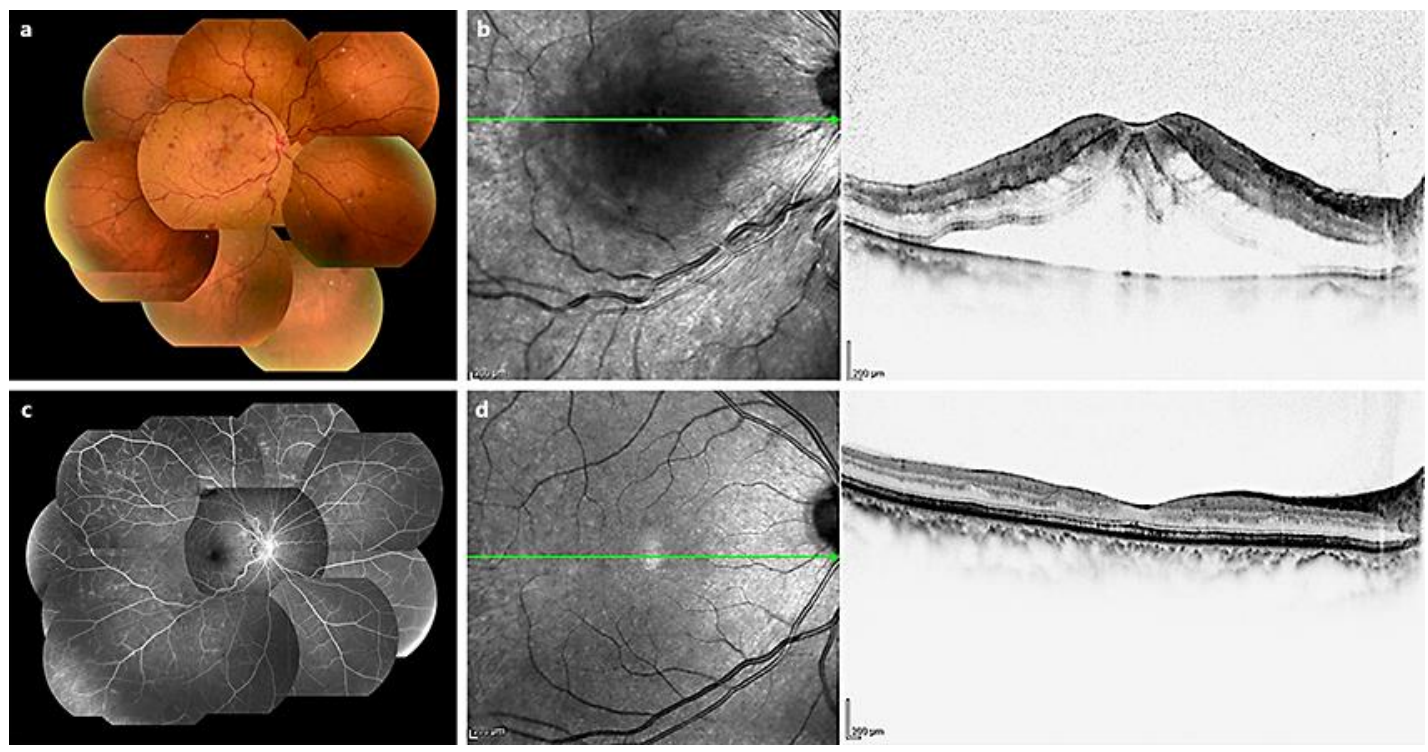

Fig. 1. Case 1. Fundus photograph, optical coherence tomographic (OCT) images, and fluorescein angiographic (FA) image of a 62-year-old woman who developed a central retinal vein occlusion (CRVO) with macular edema. She was a chronic user of antipsychotic medications. a Fundus photograph at the first visit. Her BCVA was 20/2,000 in the right eye. The tortuosity and dilatation of retinal veins with retinal hemorrhages and small cotton wool spots due to the CRVO can be seen in her right fundus. b OCT image showing marked macular edema with high reflectivity of the inner retinal layer. c FA image does not show any arterial occlusion or nonperfused areas. $\mathbf{d}$ OCT image shows a thinner central retinal thickness of $163 \mu \mathrm{m}$ at 1 year after the onset of the CRVO. 


\section{Case Reports in Ophthalmology}

\begin{tabular}{l|l}
\hline Case Rep Ophthalmol 2017;8:410-415 \\
\hline DOI: $10.1159 / 000479219$ & $\begin{array}{l}\text { ○ 2017 The Author(s). Published by S. Karger AG, Basel } \\
\text { www.karger.com/cop }\end{array}$ \\
\hline
\end{tabular}

Taki et al.: Central Retinal Vein Occlusion in 2 Patients Using Antipsychotic Drugs
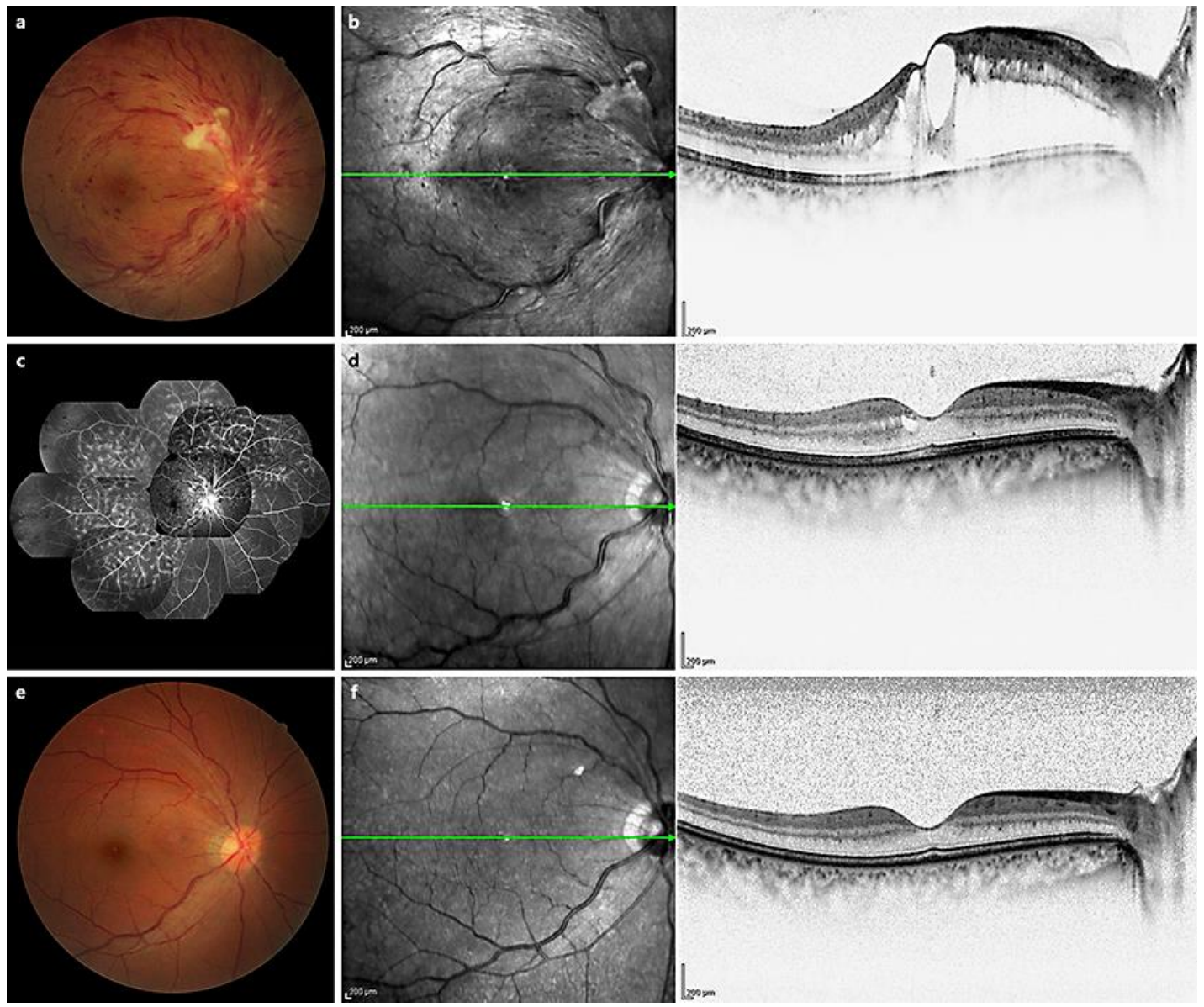

Fig. 2. Case 2. Fundus photographs, optical coherence tomographic (OCT) images, and fluorescein angiographic (FA) image of a 43-year-old man with a central retinal vein occlusion. a Fundus photograph at the first visit. His BCVA was 20/50 in the right eye. The optic disc was swollen, and the retinal veins were tortuous and dilated with hemorrhages and small cotton wool spots in the right fundus. $\mathbf{b}$ OCT shows severe macular edema. c FA shows no ischemic findings. $\mathbf{d}$ The macular edema was resolved 1 month after a single injection of ranibizumab. His BCVA recovered to 20/20 in the right eye. e Fundus photograph 1 year after the onset of the CRVO. $f$ Macular OCT 1 year after the onset of the CRVO. 